'||||||||||||||||||||||||||||||||||||||||||||||||||||||||.

\section{Sicherheit in Afrika}

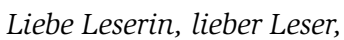

Afrika macht von sich reden. Dort ist nicht nur in der Politik Bewegung. Auf den umstrittenen Präsidenten Robert Mugabe in Simbabwe folgt nach 37 Jahren Emmerson Mnangagwa, der seinen Anhängern Demokratie, Sicherheit und Wirtschaftswachstum verspricht. Auch beim Automobil tut sich so einiges.

Gemeinsam mit wissenschaftlichen Partnern in Nigeria, Ghana, Kenia und Tansania hat die TU München ein ElektroPick-up namens aCar entwickelt, das auf der IAA 2017 vorgestellt wurde. „Es handelt sich um ein Fahrzeug, das sich die Menschen dort finanziell leisten können; es ist geländegängig und kann große Lasten transportieren“, erklärte Prof. Markus Lienkamp von der TU München. Der modulare Aufbau erlaube noch weitere Nutzungen, zum Beispiel die Wasseraufbereitung. Die Forscher verschifften das E-Fahrzeug nach Ghana, wo sie im Juli 2017 die Technik und das Transportkonzept unter lokalen Bedingungen prüften. Das aCar bestand die Tests mit Bravour. Bis zum letzten Erprobungstag kamen die einheimischen Tester mit dem Auto gut zurecht. Sie waren begeistert.

Die Afrikaner möchten nicht mehr alte Autos aus zweiter und dritter Hand der Europäer „aufbrauchen“. Denn erstklassige Technik ist auch für deren Mobilität vonnöten. So gründeten Global NCAP und Automobile Association of South Africa in Kapstadt die Initiative „Safer Cars for Africa“. Es erfolgten bereits die ersten unabhängigen Crashtest-Bewertungen einiger der beliebtesten Kompakt- und Kleinwagen Südafrikas, die $65 \%$ des Markts abdecken. Die Crashergebnisse der fünf getesteten Autos VW Polo Vivo, Datsun Go Plus, Toyota Etios, Renault Sandero und Chery QQ3 zeigen leider teilweise besorgniserregende Beurteilungen der Sicherheitsleistungen: Von vier geht es herunter auf bis zu null Sterne für den Erwachsenenschutz. Hier sollten die internationalen OEMs lieber gleich die höheren Standards aus Europa und den USA nutzen, anstatt Billigtechnik unterzujubeln.

Wie wichtig die Rolle des NCAP bei der Weiterentwicklung der Sicherheitstechnik für Pkw ist, hat sich ja eindeutig in den letzten Jahrzehnten in der westlichen Welt bestätigt. Durch den Druck „der Sterne“ mussten OEMs ihre Fahrzeuge stetig mit besseren Rückhalteund Bremssystemen ausrüsten. Das Programm NCAP, von der UNO gefördert und unterstützt, muss als Katalysator für die Verbesserung der Fahrzeugsicherheitsstandards auf der gesamten Welt dienen. Hoffentlich auch bald in Afrika. Dort sind doch schließlich keine Menschen zweiter oder dritter Klasse.

Herzliche Grüße

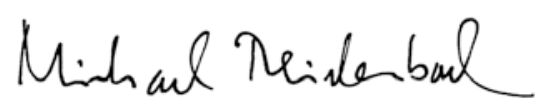

Dipl.-Ing. Michael Reichenbach Stellvertretender Chefredakteur

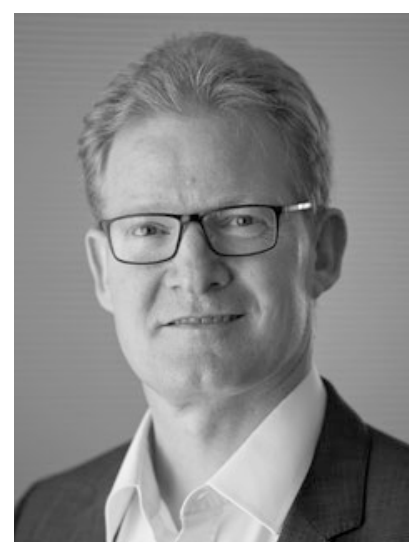

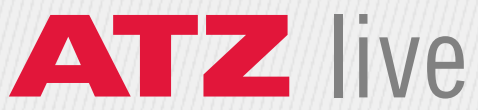

\section{Netzintegration der} Elektromobilität

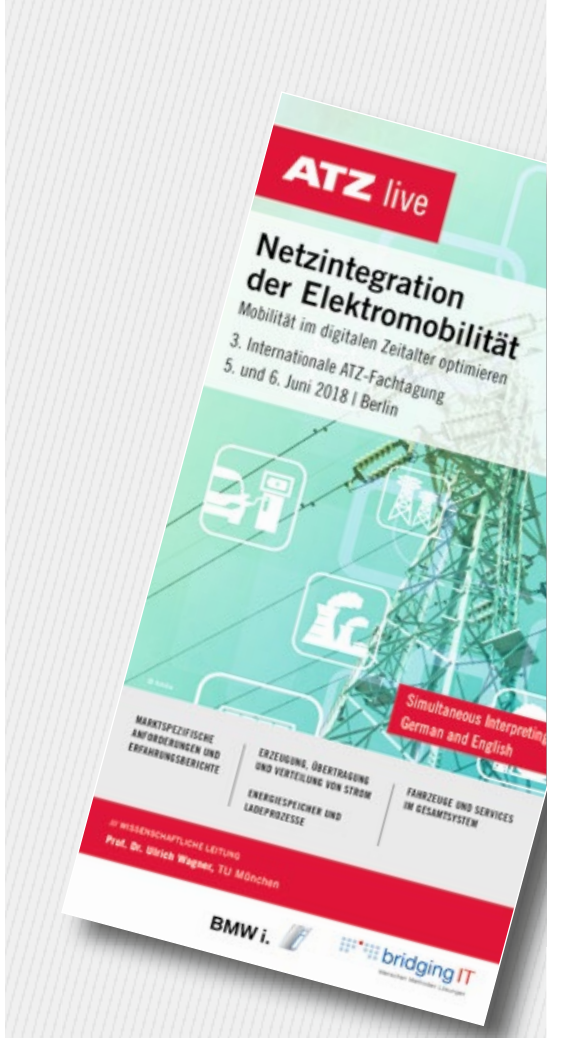

Mobilität im digitalen Zeitalter optimieren

\section{Internationale ATZ-Fachtagung 5. und 6 . Juni 2018 Berlin}

AKTUELLES TAGUNGSPROGRAMM www.ATZlive.de 